\title{
Balanço hídrico sequencial e sua respectiva erosão pluvial no município de Amparo de São Francisco - SE, Brasil
}

\author{
Sequential water balance and its respective rainfall erosion in the municipality of Amparo de São
}

\author{
Francisco - SE, Brazil
}

Balance hídrico secuencial y su respectiva erosión pluvial en el municipio de Amparo

de São Francisco - SE, Brasil

\section{Resumo}

Objetiva-se efetivar-se o cálculo do balanço hídrico sequencial entre os anos de 1963 - 2019 para Amparo de São Francisco - SE, com a finalidade de constatar a variabilidade do índice erosivo da área estudada. Os dados mensais e anuais pluviais foram adquiridos do banco de dados da Superintendência de Desenvolvimento do Nordeste e da Empresa de Assistência Técnica e Extensão Rural do estado do Sergipe, para o período acima citado. Os dados térmicos foram estimados pelo software Estima T. A metodologia aplicada foi desenvolvida por Thornthwaite. Os índices erosivos fluíram entre $7500 \mathrm{MJ} / \mathrm{mm} / \mathrm{ha} / \mathrm{ano}$ a $28000 \mathrm{MJ} / \mathrm{mm} / \mathrm{ha} / \mathrm{ano}$, ressalta-se que estes índices estão interligados as flutuações pluviais que registrou-se com grande magnitude e em pequeno intervalo de tempo. Os resultados do balanço hídrico mostraram que as condições locais contidas pelo alto índice pluvial, pode ocasionar elevada erosividade e nos mostram que esta metodologia deve ser utilizada para estudos futuros, envolvendo a mesma temática de iniciativa deste estudo em discussão.

Palavra-chave: Planejamento agropecuário; Evapotranspiração; Sustentabilidade hídrica.

\begin{abstract}
The objective is to carry out the calculation of the sequential water balance between the years 1963 - 2019 for Amparo de São Francisco - SE, with the purpose of verifying the variability of the erosive index of the studied area. The monthly and annual rainfall data were acquired from the database of the Northeast Development Superintendence and from the Technical Assistance and Rural Extension Company of the state of Sergipe, for the period mentioned above. The thermal data were estimated by the Estima T software. The applied methodology was developed by Thornthwaite. The erosive rates flowed between $7500 \mathrm{MJ} / \mathrm{mm} / \mathrm{ha} / \mathrm{year}$ at $28000 \mathrm{MJ} / \mathrm{mm} / \mathrm{ha} / \mathrm{year}$, it is noteworthy that these indexes are interconnected to rainfall fluctuations that registered with great magnitudes and in a short time interval. The results of the water balance showed that the local conditions contained by the high rainfall index can cause high erosivity and show us that this methodology should be used for future studies involving the same theme of initiative of this study under discussion.
\end{abstract}

Keywords: Agricultural planning; Evapotranspiration; Water sustainability.

\section{Resumen}

El objetivo es realizar el cálculo del balance hídrico secuencial entre los años 1963 - 2019 para Amparo de São Francisco - SE, con el propósito de verificar la variabilidad del índice erosivo del área estudiada. Los datos de 
precipitación mensual y anual se obtuvieron de la base de datos de la Superintendencia de Desarrollo del Nordeste y de la Empresa de Asistencia Técnica y Extensión Rural del estado de Sergipe, para el período mencionado anteriormente. Los datos térmicos fueron estimados por el software Estima T. La metodología aplicada fue desarrollada por Thornthwaite. Las tasas de erosión fluyeron entre $7500 \mathrm{MJ} / \mathrm{mm} / \mathrm{ha} / \mathrm{año}$ a $28000 \mathrm{MJ} / \mathrm{mm} / \mathrm{ha} / \mathrm{año}$, es de destacar que estos índices están interconectados con las fluctuaciones de las precipitaciones que se registraron con grandes magnitudes y en un corto intervalo de tiempo. Los resultados del balance hídrico mostraron que las condiciones locales contenidas por el alto índice de precipitaciones pueden causar alta erosividad y nos muestran que esta metodología debe ser utilizada para futuros estudios que involucren el mismo tema de iniciativa de este estudio en discusión.

Palabras clave: Planificación agrícola; Evapotranspiración; Sostenibilidad del agua.

\section{Introdução}

É fundamental que sejam levantadas e trabalhadas informações a respeito dos recursos hídricos na região visando avaliar medidas mitigadoras aos impactos negativos ou danos ambientais que possam ser gerados pelo empreendimento. Desta forma, a determinação do BHC é uma ferramenta útil para auxiliar na tomada de decisão. Para Rocha, Pinheiro \& Costa (2020), a gestão dos recursos hídricos é uma ferramenta importante para promover sustentabilidade hídrica.

Medeiros \& Holanda (2020) realizaram o balanço hídrico sequencial (BHS), com a finalidade de verificar as flutuações climáticas, determinando e disponibilizando as contribuições para elaborações de planejamento agropecuário. O BHS fornece informações detalhadas das variáveis climáticas, ocasionando subsídios aos poderes governamentais e aos elaboradores de projetos para um desenvolvimento sustentável das produções na área estudada. Os valores da evapotranspiração mensais apresentam conexão com as coordenadas geográficas e a orografia.

Medeiros (2020) realizar o balanço hídrico sequencial para o município de São Bento do Una visando determinar a contribuição do armazenamento e represamento d'água, em relação à crise hídrica, gerando e disponibilizando subsídios para elaboração de planejamento e projeto. Os impactos climáticos vêm causando alterações no balanço hídrico regional para a última década. A degradação ambiental, o efeito local da ação antrópica, vem antecipando o processo de mudança do clima regional, afetando diretamente as condições do regime pluvial e a disponibilidade d'água no solo. A necessidade da captação d'água de chuva e de outras fontes de armazenamento auxiliam a sobrevivência humana, animal, vegetal e contribuem para os setores agropecuário e em particular o setor avícola da região.

França et al, (2020a) estimaram o balanço hídrico normal em face dos fenômenos El Niño(a), visando à ocorrência da variabilidade erosiva para Amparo de São Francisco - SE, disponibilizando informações aos tomadores de decisões governamentais para que possam realizar planejamento que visem conter perdas de solo na região. Os índices de aridez tem uma maior contribuição para o processo erosivo, foi registrado na fase de ocorrência de La Niña (3,63\%), seguidamente dos períodos de El Niño (21,78\%) e da série pluvial (1963-2019) (35,85\%). Os índices hídricos apresentaram as seguintes variabilidades para o período da série $(-12,37 \%)$, El Niño (10,96\%) e La Niña (71,06\%). Os índices de umidade oscilaram com 8,76\% na série, $24,02 \%$ no El Niño e 73,23\% na La Niña. Sabe-se que quanto menor o Ia maior a ocorrência da erosão.

França et al, (2020b) avaliaram as condições hídricas por meio do panorama climático da variabilidade da capacidade de campo visando detectar as flutuações erosivas do solo, no município de Amparo de São Francisco - Sergipe, pelo cálculo do balanço hídrico. A metodologia aplicada para o computo do balanço hídrico foi de Thornthwaite. As capacidades de campo de $25 \mathrm{~mm} ; 50 \mathrm{~mm}$ e $75 \mathrm{~mm}$ registraram índices erosivos altos. A capacidade de campo de $100 \mathrm{~mm} ; 125 \mathrm{~mm}$ e $150 \mathrm{~mm}$ registraram erosividade moderada, e índices erosivos fracos para a capacidade de $175 \mathrm{~mm}$. Os índices pluviais para as capacidades de campos estudadas deverão ocasionar mais incidências erosivas onde se esperam chuvas fortes com grandes 
magnitudes e em curto intervalo de tempo. Os resultados obtidos indicam situações críticas das condições do solo da área em estudo, o que poderá ocasionar grandes impactos para os recursos hídricos e a prática de culturas de sequeiro.

Matos et al. (2020) avaliaram o balanço hídrico normal (BHN) e sequencial (BHS) para a cidade de Barbalha - CE, gerando informações que podem ser utilizadas para elaboração de planejamento agrícola regional. Os autores mostraram que a evapotranspiração da região é superior à precipitação pluviométrica de maio a dezembro, resultando em déficit d'água no solo durante este período. Portanto, existe a necessidade de irrigação para evitar redução tanto em crescimento quanto em produtividade das culturas. Os resultados fornecem suporte para o planejamento das atividades agrícolas do município em estudo.

França et al. (2019) mostraram a análise do balanço hídrico entre 2000-2016 comparou com o BH do ano 2016 visando entender e verificar as oscilações das deficiência hídrica e sua influência do armazenamento d'água em Serra Talhada - PE. As informações meteorológicas mostram que mudanças ocorreram e que os habitantes deverão no futuro mudar as técnicas em relação aos plantios e condições de sobrevivência. Os autores destacaram que a tendência de acréscimo na temperatura e nos índices evapotranspirativos poderão originar eventos extremos pluviais em intervalo de tempo curto e com alta magnitude.

Matos et al. 2019; Passos et al. 2016; Holanda \& Medeiros (2019) o balanço hídrico é obtido computando a demanda e a disponibilidade hídrica por meio da chuva, evapotranspiração real e potencial, armazenamento d’água no solo, da deficiência e do excedente hídrico. Através do conhecimento de entrada e saída d'água no solo, permite-se desta forma a classificação climática da região.

Medeiros (2016) elaborou o balanço hídrico mensal para a cidade Matinhas (PB), objetivando o planejamento a citricultura. Resultando para os meses de agosto a março com deficiência hídrica totalizando 354,5 mm, registrando excedente hídrico entre os meses de junho e julho, evapotranspirando 32\% acima dos índices pluviométricos, evaporação anual de 906,7 mm. É de fundamental interesse a discussão de planos alternativos e principalmente eficazes, com redução do consumo e desperdício d'água em tempos de escassez (Augusto, et al. 2012).

Tem-se por objetivo efetivar-se o balanço hídrico sequencial dos anos 1963 - 2019 para Amparo de São Francisco SE, com o intuito de verificar a contribuição erosiva para a área estudada.

\section{Material e Método}

O município de Amparo de São Francisco posiciona-se no setor nordeste do Estado, tem como limite: Telha a Leste e a Sul, Canhoba a Oeste, o Estado de Alagoas a Norte. Com uma área de 39,8 $\mathrm{km}^{2}$ e altitude de 51 metros e de coordenadas geográficas de $10^{\circ} 08^{\prime} 04^{\prime \prime}$ sul e $36^{\circ} 55^{\prime} 46^{\prime \prime}$ Oeste. (Figura 1). 
Figura 1. O estado do Sergipe e o posicionamento da cidade de Amparo de São Francisco.

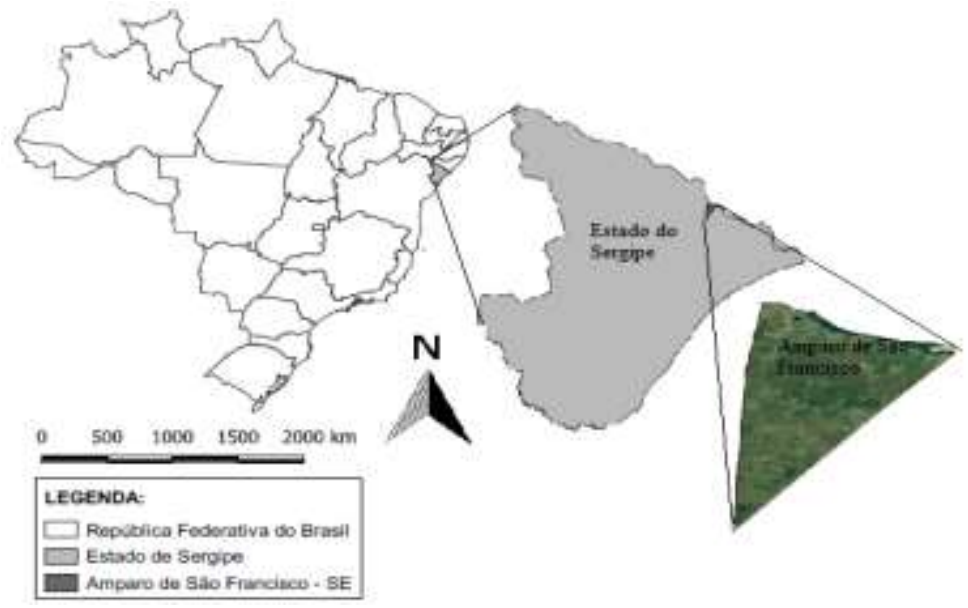

Fonte: França (2020).

Amparo de São Francisco está localizado em uma região e se distingue com duas estações bem definidas, um período chuvoso fluindo de fevereiro a agosto e seu período seco, compreendido entre setembro a janeiro. Segundo a classificação climática de Köppen (1928) e de Köppen \& Geigen (1931), Amparo de São Francisco tem o clima "As” (quente e úmido Tropical chuvoso). Estudos com os autores (Medeiros, 2020); (Alvares et al. 2014). Conseguiram constatar o mesmo tipo climático da área estudada

É conveniente lembrar que a quadra chuvosa é caracterizada por frequentes e intensas chuvas em pequenos intervalos de tempo, favorecendo o surgimento de erosões, visto que pela frequência de chuva em um breve período, a água não consegue infiltrar no solo e acaba realizando o carreamento das partículas solidas.

A área de estudo posiciona-se na bacia hidrográfica do rio São Francisco, onde o seu escoamento d'águas tende a ir ao encontro do rio principal e desta forma começa a modelar o terreno. Tendo em vista que as águas decorrentes das chuvas durante o processo do escoamento superficial procuram caminhos naturais para o seu escoamento, cuja tendência é a de escoar de pontos elevados para pontos baixos do percurso principal do rio São Francisco. Os tipos de solos predominantes na região são do tipo neossolo flúvico nas margens do rio São Francisco e neossolo litólico na sua topo sequência, na orientação sul.

Utilizaram-se dados de precipitações mensais e anuais fornecidos pela Superintendência de Desenvolvimento do Nordeste (Sudene, 1990); Empresa de Assistência Técnica e Extensão Rural do estado do Sergipe (Emater-se, 2020) entre 1963 a 2019.

Utilizaram-se dos dados térmicos estimadas pelo software Estima_T (Cavalcanti \& Silva, 1994; Cavalcanti et al. 2006, para o mesmo período pluvial. Determinaram-se os coeficientes da função quadrática pelo inverso de sua distância para as temperaturas média, máxima e mínima mensal em função das coordenadas locais: longitude, latitude e altitude de (Cavalcanti \& Silva 2006) expressa pela equação:

$$
\mathrm{T}=\mathrm{C}_{0}+\mathrm{C}_{1} \lambda+\mathrm{C}_{2} \varnothing+\mathrm{C}_{3} \mathrm{~h}+\mathrm{C}_{4} \lambda^{2}+\mathrm{C}_{5} \emptyset^{2}+\mathrm{C}_{6} \mathrm{~h}^{2}+\mathrm{C}_{7} \lambda \varnothing+\mathrm{C}_{8} \lambda \mathrm{h}+\mathrm{C}_{9} \varnothing \mathrm{h}
$$

Em que:

$\mathrm{C}_{0}, \mathrm{C}_{1}, \ldots ., \mathrm{C}_{9}$ são as constantes;

$\lambda, \lambda^{2}, \lambda \varnothing, \lambda \mathrm{h}$ longitude;

$\varnothing, \varnothing^{2}, \lambda \varnothing$ latitude; 
$h, h^{2}, \lambda h, \varnothing \mathrm{h}$ altura.

Também estimaram a série temporal de temperatura, adicionando a esta à anomalia de temperatura do Oceano Atlântico Tropical (Cavalcanti et al., 2006).

$$
\mathrm{T}_{\mathrm{ij}}=\mathrm{T}_{\mathrm{i}}+\mathrm{AAT}_{\mathrm{ij}} \quad \mathrm{i}=1,2,3, \ldots, 12 \quad \mathrm{j}=1950,1951,1952, \ldots .2019
$$

Em que:

$\mathrm{i}=1,2,3, \ldots, 12$

$j=1950,1951,1952,1953, \ldots, 2019$.

Utilizaram-se da metodologia desenvolvida por Thornthwaite (1948) para o cálculo do BHS em escala mensal para a área estudada, ou seja, o BHS, elaborado a partir das normais climatológicas de temperatura e precipitação média. Através da contabilização do suprimento natural d'água ao solo, por meio da pluviosidade e da demanda evapotranspirativa, considerando um nível máximo possível de armazenamento. O BHS fornece estimativa da evapotranspiração, deficiência hídrica, excedente hídrico e armazenamento efetivo d'água no solo, podendo ser elaborado desde a escala diária até a mensal (Camargo, 1971). Nos cálculos para a obtenção do BHS utilizou-se do valor de CAD representativos dos solos - CAD = $100 \mathrm{~mm}$ para um solo com alta capacidade de armazenamento no município onde a obtenção do BHS foi computado através de planilha eletrônica elaboradas por Rolim et al. (1998) e adapta por Medeiros (2019).

\section{Resultados e Discussões}

Na Figura 2 observam-se as oscilações pluviais anuais e médias histórica dos anos de 1963-2019 para o município de Amparo de São Francisco - Sergipe. O município registra uma média histórica de 1130,4 mm. As elevadas precipitações ocorreram nos anos de 1963 a 1967, 1973. Os menores índices pluviais registou-se em 1970, 1980, 1993, 2012, 2016 e 2018. Estas variabilidades estão em conformidades com os estudos de Marengo (2014); IPCC (2014); Holanda \& Medeiros (2020).

Figura 2. Índices pluviais anuais e média histórica de 1963-2019 para Amparo de São Francisco - Sergipe.

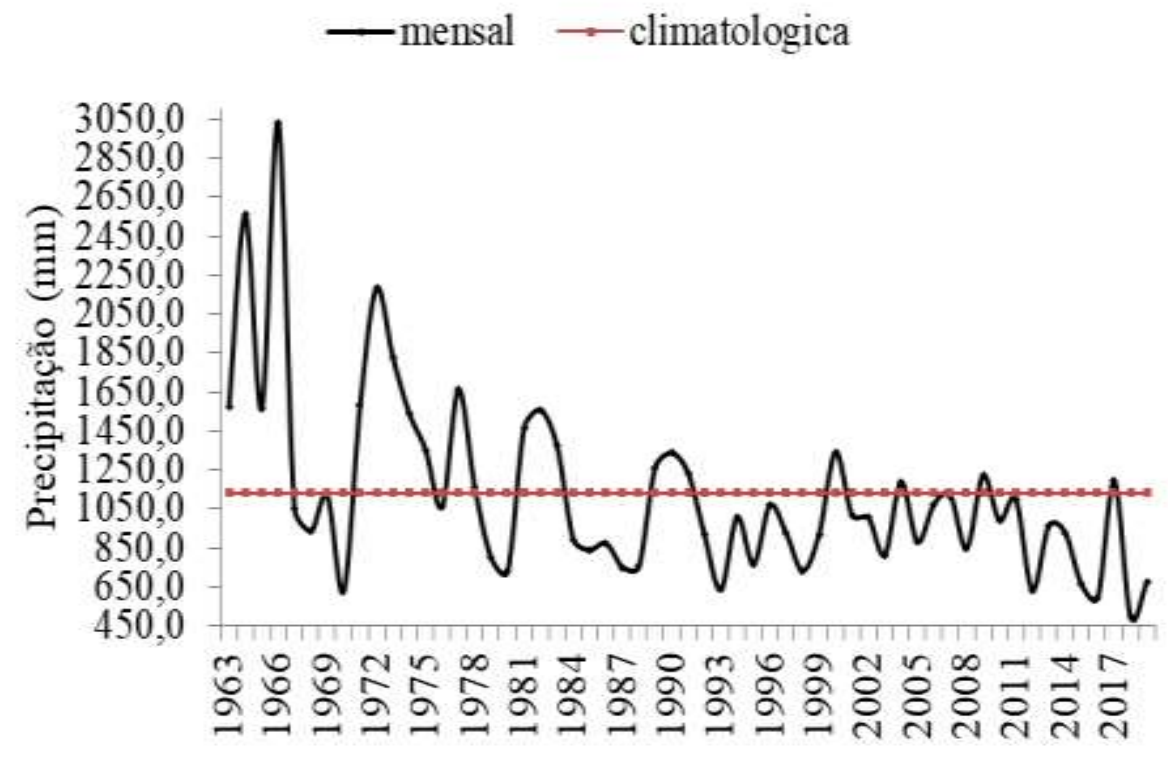

Fonte: Medeiros, (2020).

Na Figura 3 destacam-se as anomalias pluviais anuais compreendidas entre 1963-2019 para Amparo de São Francisco - Sergipe. As anomalias pluviais fluíram de $1850 \mathrm{~mm}$ (1966) a -590,3 mm (2018). Com dezessete anos com precipitações 
superiores a média; nove anos com chuvas próximo a média climatológica e trinta anos com chuvas inferiores a média climatológica. O estudo de Medeiros (2019); Marengo, Schaeffer \& Pinto (2017); Xavier \& Dornelins (2005) mostraram similaridades com as discussões e suas flutuações pluviais neste estudo.

Figura 3. Anomalias pluviais anuais do período 1963-2019 em Amparo de São Francisco - Sergipe.

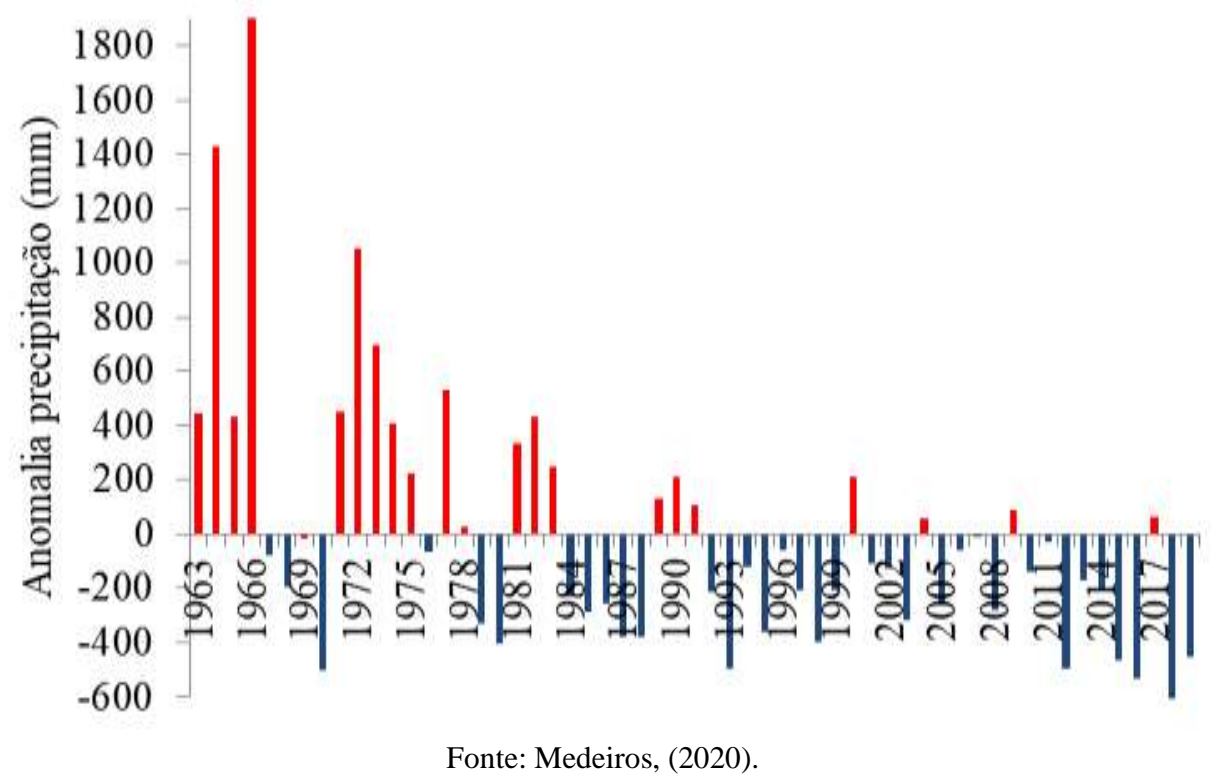

Na Figura 4 observam-se os índices térmicos anuais e médios climatológicos de 1963-2019 para Amparo de São Francisco. As flutuações térmicas fluíram de $25,3{ }^{\circ} \mathrm{C}(1975)$ a $26,5^{\circ} \mathrm{C}$ em 2015 . Os anos de menores temperaturas registraramse em: 1964 com $25,5^{\circ} \mathrm{C} ; 1967\left(25,6^{\circ} \mathrm{C}\right) ; 1971,1974$ e $1975\left(25,3^{\circ} \mathrm{C}\right) ; 19786\left(25,5^{\circ} \mathrm{C}\right)$, As maiores temperaturas tiveram registros nos anos de $1971\left(26,4^{\circ} \mathrm{C}\right) ; 1998$ e $2015\left(26,5^{\circ} \mathrm{C}\right)$. A temperatura média climatológicas registrou aumentos gradativos de $0,2^{\circ} \mathrm{C}$ a partir do ano de 1983. Estudos como o de Medeiros \& Cavalcanti (2020); Medeiros (2020) e Medeiros et al. (2018) corroboram com os resultados discutidos.

As temperaturas médias climáticas fluíram por volta dos $25,7^{\circ} \mathrm{C}$ entre 1963 a 1983, entre a década 1984-1993 ocorreu acréscimo de $0,3^{\circ} \mathrm{C}$. A oscilação climática dos anos de 1994 a 2012 foi de aumento de $0,2^{\circ} \mathrm{C}$ e entre 2103 a 2019 registrou-se o maior aumento térmico da área estudada.

Figura 4. Índices térmicos anuais e médios climatológica de 1963-2019 para Amparo de São Francisco - Sergipe. 


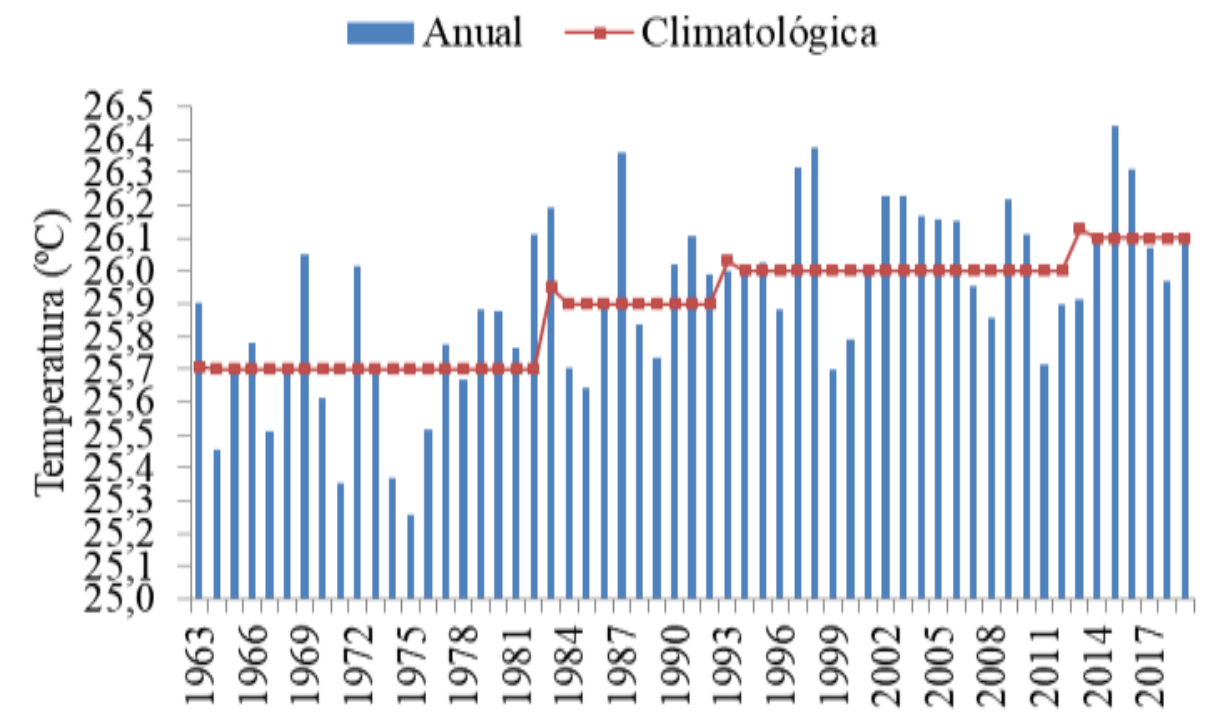

Fonte: Medeiros, (2020).

Entre 1990 a 2019 registraram-se anomalias positivas com flutuações oscilando de $0,1^{\circ} \mathrm{C}(2013)$ a $0,6^{\circ} \mathrm{C}$ em 2015 . As maiores anomalias registraram-se em 1987 e 1998 (0,5 $\left.{ }^{\circ} \mathrm{C}\right) ; 2015$ (0,6 $\left.{ }^{\circ} \mathrm{C}\right)$, exceto os anos de 1999; 2000; 2008 e 2011. Os estudos de Marengo et al, (2015); IPCC (2014) corroboram com os resultados discutidos.

Com anomalias térmicas abaixo da normal climatológicas registraram-se em 1964 a 1998 com oscilações de $0,1^{\circ} \mathrm{C}$ e para os anos de 1979; 1980; 1996. E os anos de 1971; 1974 e 1975 ocorreram anomalias inferiores aos $-0,5^{\circ} \mathrm{C}(\mathrm{Figura} 5)$.

Figura 5. Anomalias térmicas anuais de 1963-2019 para Amparo de São Francisco - Sergipe.

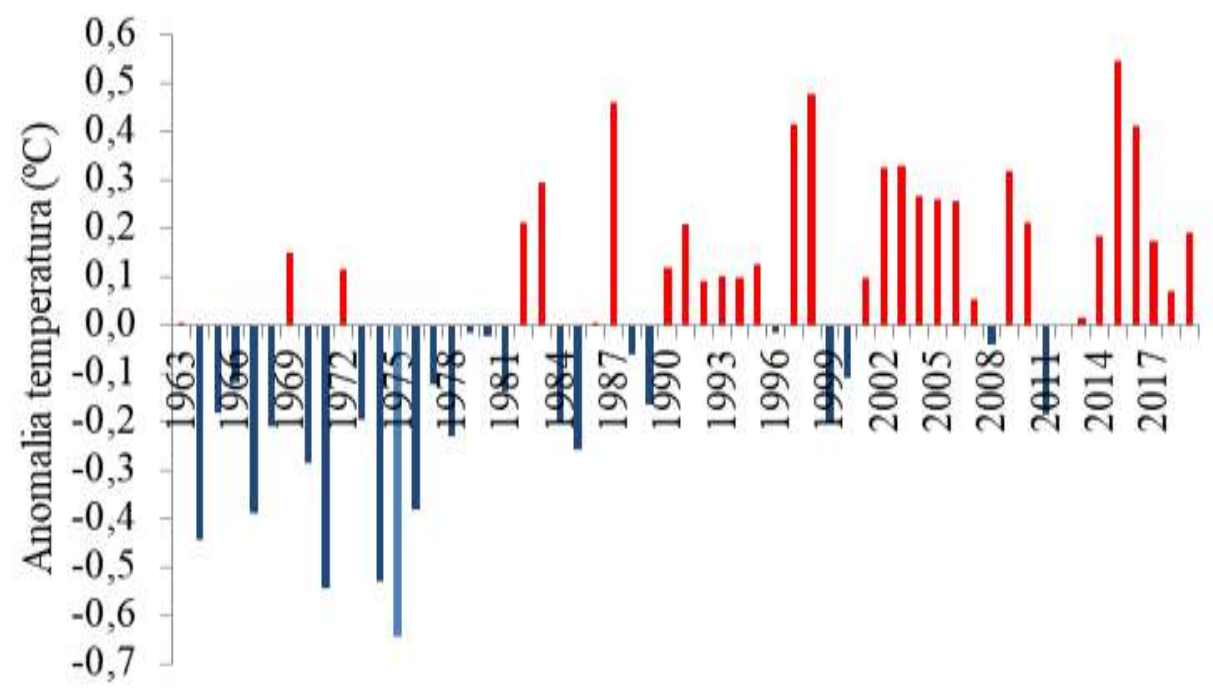

Fonte: Medeiros, (2020).

A evapotranspiração (ETP) é um dos elementos climáticos de maior importância para o ciclo hidrológico, contrafazendo o equilíbrio d'água na superfície terrestre, variável meteorológicas que é aplicada em estudos da hidrologia, 
agroecologia, irrigação e outras áreas afins (Fu et al., 2009; Roderick et al., 2009). Resultados demonstram que a magnitude das tendências evapotranspiradas são fatores determinantes, que variam muito de região para região. Estudos adicionais sobre a evapotranspiração e registros em diferentes regiões dos países tropicais é sem dúvida útil para fornecer mais evidências e entendermos melhor a variabilidade e a tendência da evapotranspiração global.

Na Figura 6 observam-se o poder evapotranspirativo anual e da média histórica de 1963-2019 para Amparo de São Francisco - Sergipe, com flutuações oscilando entre $76 \mathrm{~mm}$ a $175 \mathrm{~mm}$. Entre 1982 a 2017 centram-se os maiores picos evapotraspirativos. Com índices evaporativos menores de 80 mm registram-se os anos de 1964, 1967 e 1970.

As médias históricas decadais apresentou redução entre 1971 a 1980, seguidamente de aumentos para os demais anos em estudos. As chuvas ocorridas entre 1992 a 2019 fluíram abaixo da evapotranspiração, não sendo suficiente para consentir a diferença evaporativa do período, tornando-se inviável para produção agrícola, para tanto os cultivos deverão ser complementados através da prática da irrigação para suprir as necessidades hídricas das culturas (Medeiros, Matos, Silva. \& Silva, 2015).

Os resultados apresentados e discutidos dos índices evapotranspirativos corroboram com vários estudos como os dos autores França, et al. (2019); Medeiros, Gomes Filho \& Costa Neto (2014); Matos, Silva \& Medeiros (2014) realizados para a região semiárida do Nordeste brasileiro, os quais encontraram similaridade com as discussões e com os índices evapotranspirativos apresentadas neste artigo.

Figura 6. Flutuações evapotranspirativas anuais e média histórica de 1963-2019 para Amparo de São Francisco - Sergipe.

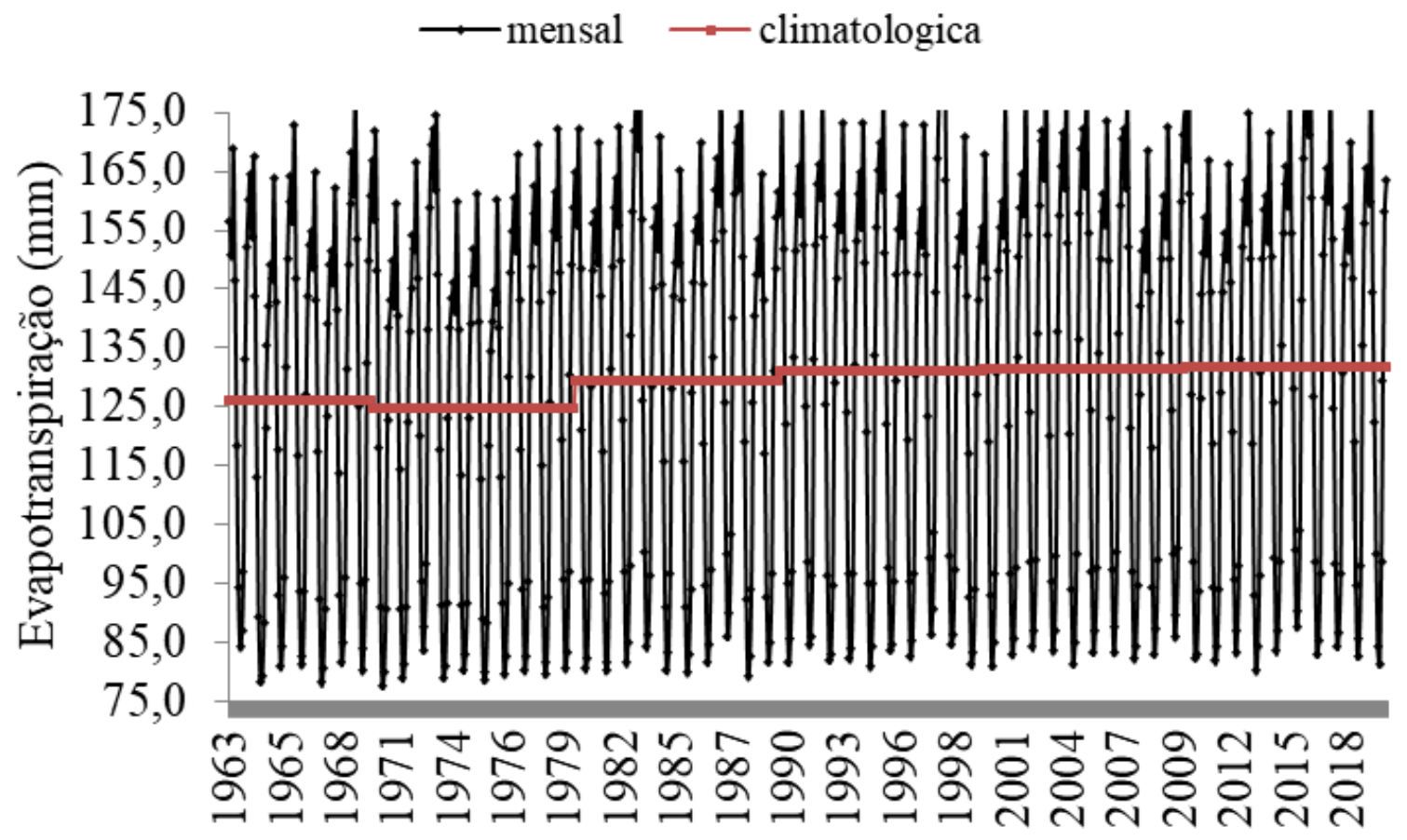

Fonte: Medeiros, (2020).

Na Figura 7 têm-se as flutuações evaporativas anuais e das médias históricas de 1963-2019 para Amparo de São Francisco - Sergipe. As flutuações de 0,0 mm nos anos de 1970; 1993; 1995; 2001; 2006; 2016 e 2017 a 180 mm 2003 e 
2008. Estas oscilações foram decorrentes das variabilidades dos sistemas sinóticas transientes regionais e locais. Destacam-se ainda oscilações entre $60 \mathrm{~mm}$ a $90 \mathrm{~mm}$ com maiores predominâncias entre a série estudada.

Na evaporação média histórica entre os anos 1963-1970; 1983-1990; 1993-2000 registrou-se redução de 2 mm; redução de 4 mm entre 1973-1980 e entre 2010-2019 registrou evaporação média histórica superior a 5 mm.

Estudos como os dos autores Matos et al. (2019) descreveram que as menores taxas evaporadas foram observadas nos meses frios e as maiores nos meses quente do ano. Os resultados encontrados pelos autores têm similaridades com os do presente estudo. Na ocasião em que o solo não alcançar a suplementação da precipitação no acolhimento da evapotranspiração, acontecerá deficiência hídrica (Borsato, 2012).

Figura 7. Índices evaporativos anuais e médias histórica de 1963-2019 para Amparo de São Francisco - Sergipe.

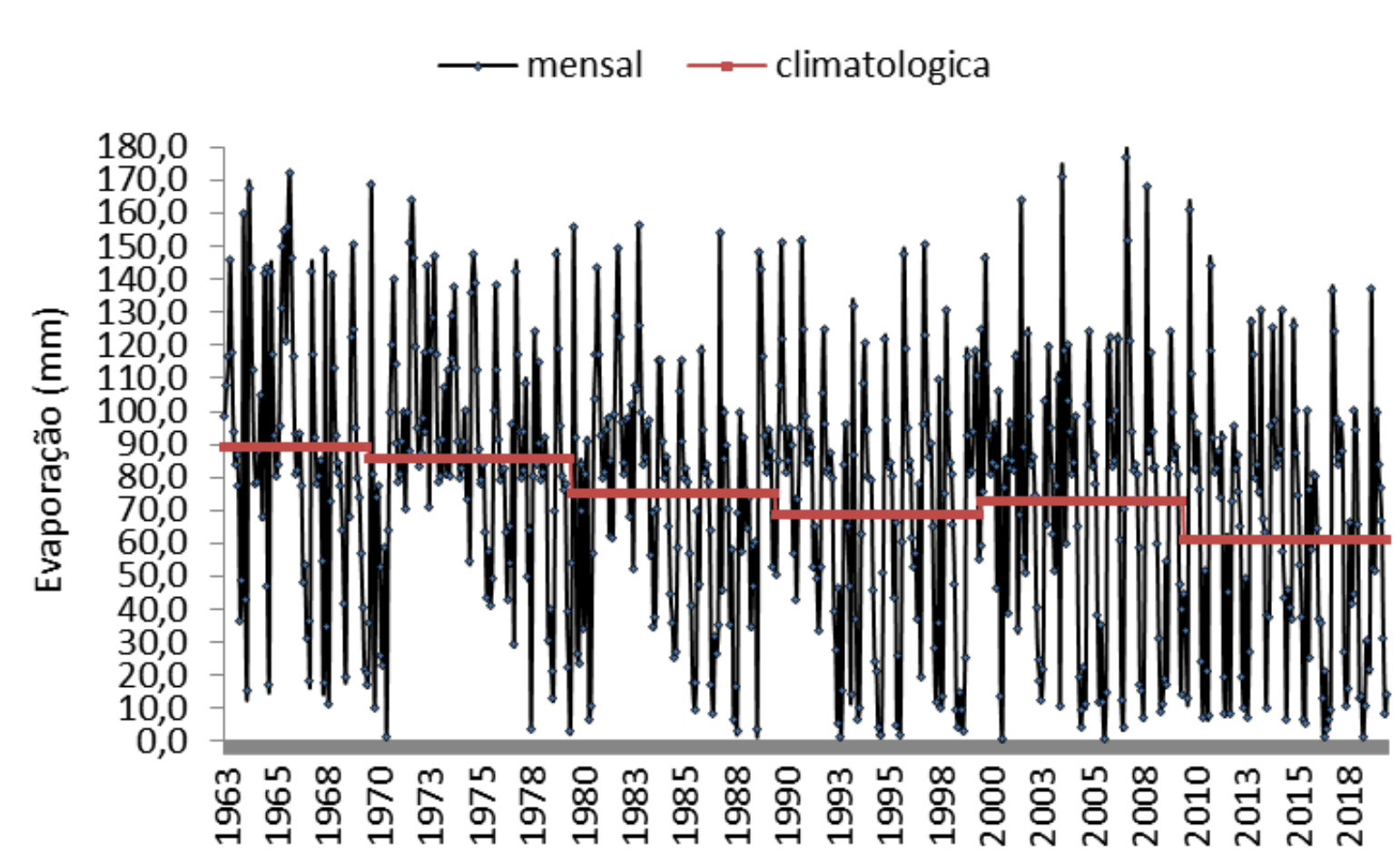

Fonte: Medeiros, (2020).

Na Figura 8 tem-se as flutuações das deficiências hídricas anuais e médias históricas de 1963-2019 para Amparo de São Francisco - Sergipe. Observa-se que entre 2000 a 2019 registraram-se as maiores deficiências hídricas fluindo de 100 mm a 180 mm. Nos anos 1970-1976 os índices de deficiências hídricas foram menores que 100 mm. As médias históricas das deficiências hídricas registraram aumentos gradativos com flutuações de 1 a 6 mm conforme a Figura 8.

França et al. (2019); Medeiros et al. (2020); (Matos, Silva \& Medeiros 2010) mostraram que para avaliar se um determinado local ocorre deficiência ou excesso d’água durante o ano, considerar-se-á dois elementos; a precipitação, responsável pelo aumento da umidade do solo e a evapotranspiração, responsável pela retirada de umidade no solo. Estes estudos vem a corroborar com os resultados discutidos.

Figura 8. Oscilações das deficiências hídricas anuais e médias histórica de 1963-2019 para Amparo de São Francisco -

\section{Sergipe.}




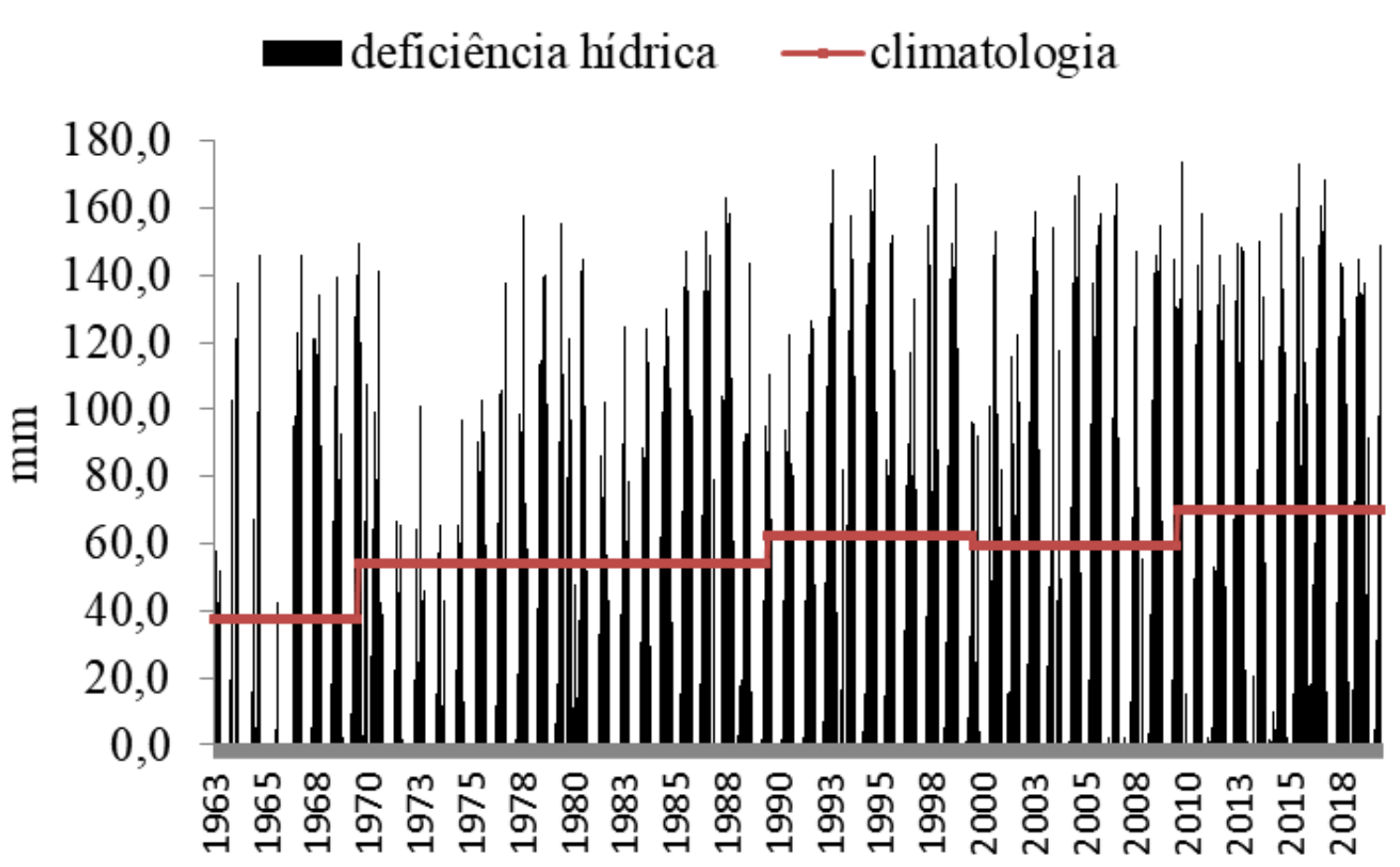

Fonte: Medeiros, (2020).

As oscilações dos excedentes hídricos anuais e médias históricas de 1963-2019 para Amparo de São Francisco Sergipe (Figura 9). Os maiores excedentes hídricos registrados na série estudada foram para os anos 1964; 1966; 1977; 2009 e 2017 com oscilações fluindo entre $165 \mathrm{~mm}$ a $675 \mathrm{~mm}$. Os menores excedentes hídricos anuais com índices abaixo de $50 \mathrm{~mm}$ foram os anos de 1979; 1984; 1988; 1993; 1997; 2003; 2013 e 2015.

Entre os anos de 1963-1970 registrou-se um decréscimo de 2,5 mm na média histórica, redução de 1,8mm entre os anos de 1970-1980, entre 1979-2000 e entre 2011-2019 ocorreu uma redução de 1,5 mm, entre os anos de 2000-2010 registrou-se aumento de $1,8 \mathrm{~mm}$ nos excedentes hídricos climatológicos.

Estudos como os dos autores França et al. (2019); França et al. (2019), Medeiros et al. (2020) apresentam semelhanças de dados e discussões e corroboram com os resultados discutidos.

Figura 9. Oscilações das excedentes hídricos anuais e médias histórica de 1963-2019 para de Amparo de São Francisco Sergipe. 


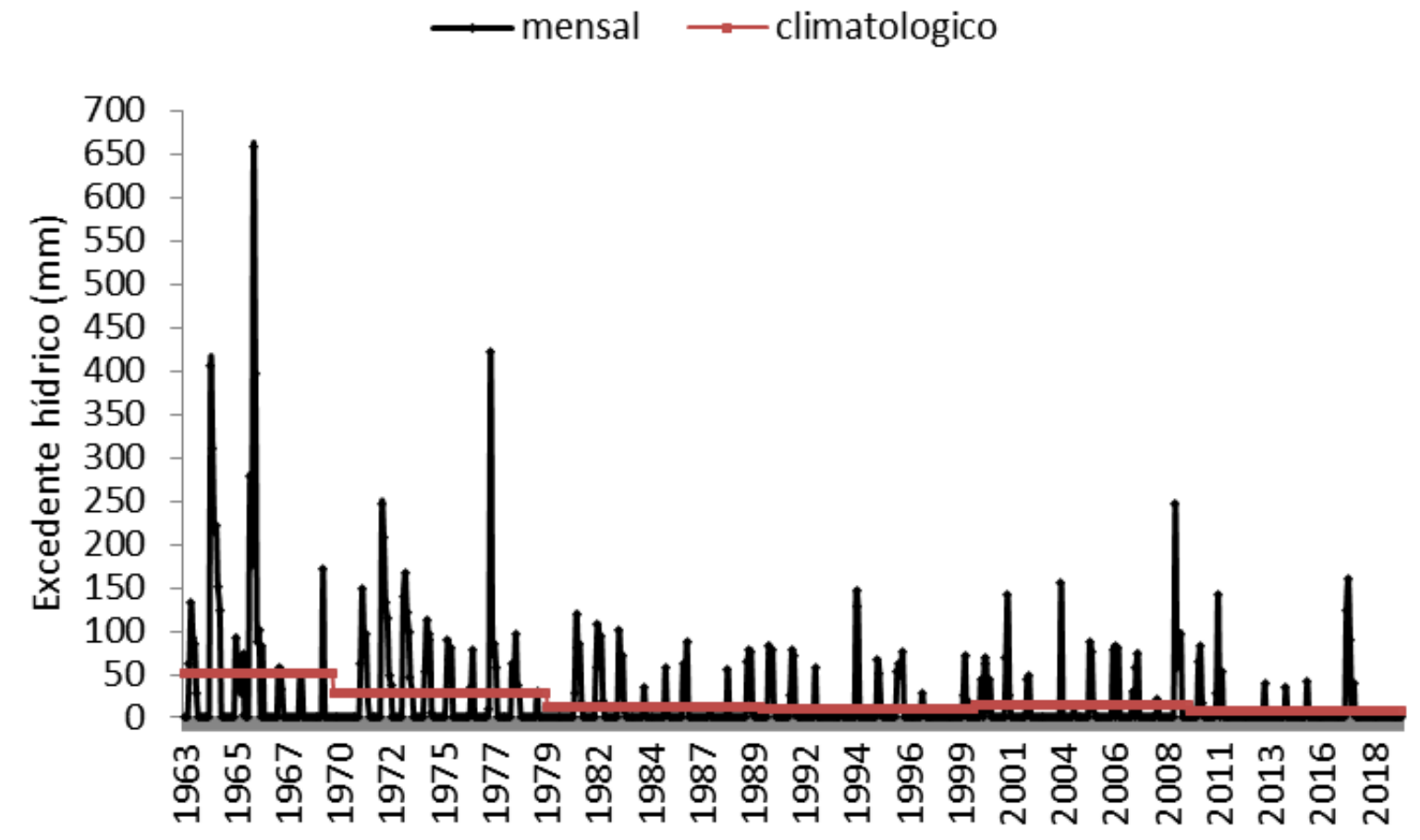

Fonte: Medeiros, (2020).

Na Figura 10 têm-se as oscilações das variabilidades dos índices de: Umidade (Iu); Aridez (Ia) e Hídrico (Ih) no período de 1963-2019 para o município de Amparo de São Francisco - Sergipe.

O índice de umidade oscila entre $-60,0 \mathrm{~mm}$ a 98,8 mm, os maiores índices foram registrados nos anos de 1963; 1966; 1972; 1977; 2009 e 2017. Os menores Iu foram observados nos anos de 1970; 1980; 1984; 1987; 1993; 1998; 2001; 2008; 2012 e 2016 as flutuações estão em conformidades com os estudos de Vilar \& Medeiros (2019); Silva; Franca; Medeiros \& Holanda (2019).

Os índices de aridez fluíram entre 22\% (1963) a 60\% (2019). Entre os anos de 1993 a 2018 observam-se magnitudes irregulares e intensas, exceto o ano de 2000. Nos anos de 1963 a 1992 destacam-se que a magnitude e suas intensidades foram mais espaçadas, estudos que corroboraram com os resultados em discussões foram Holanda, Medeiros; França; Rolim Neto (2019). Os menores índices de erosão e suas altas erosivibilidades foram registrados nos anos de 1964-1966; 1972-1975; 1981-1982; 2000.

As variabilidades dos índices hídricos fluíram intermediariamente aos índices de umidade e aridez.

Figura 10. Variabilidade dos índices de: Umidade (Iu); Aridez (Ia) e Hídrico (Ih) no período de 1963-2019 para o município de Amparo de São Francisco - Sergipe. 


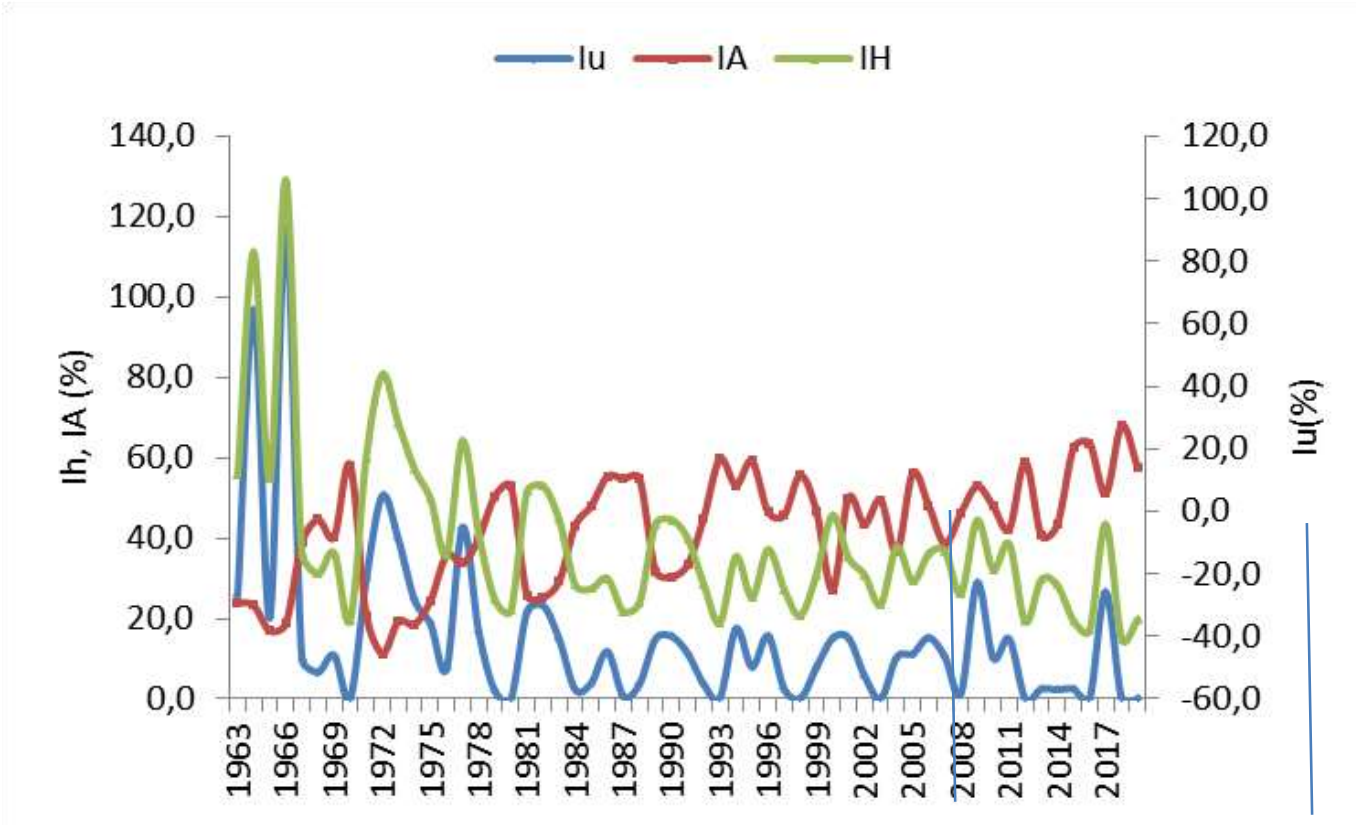

Fonte: Medeiros, (2020).

Figura 11. Índices erosivos anuais do período de 1963-2019 para o município de Amparo de São Francisco - Sergipe. Nos anos de 1963-1966 registraram-se os maiores índices erosivos de alta magnitude fluindo entre $28100 \mathrm{MJ}$. mm/ha.ano a 79000 MJ. mm/ha.ano. Os índices erosivos fluíram entre 7500 MJ. mm/ha.ano a 28000 MJ. mm/ha.ano, ressalta-se que este índice erosivo estão interligados as flutuações pluviais que registrou-se com esparsas magnitudes entre os anos de 1972-1992 e entre os anos de 1994 a 2019 baixas magnitudes em curto intervalo de tempo.

Figura 11. Índices erosivos anuais do período de 1963-2019 para o município de Amparo de São Francisco - Sergipe.

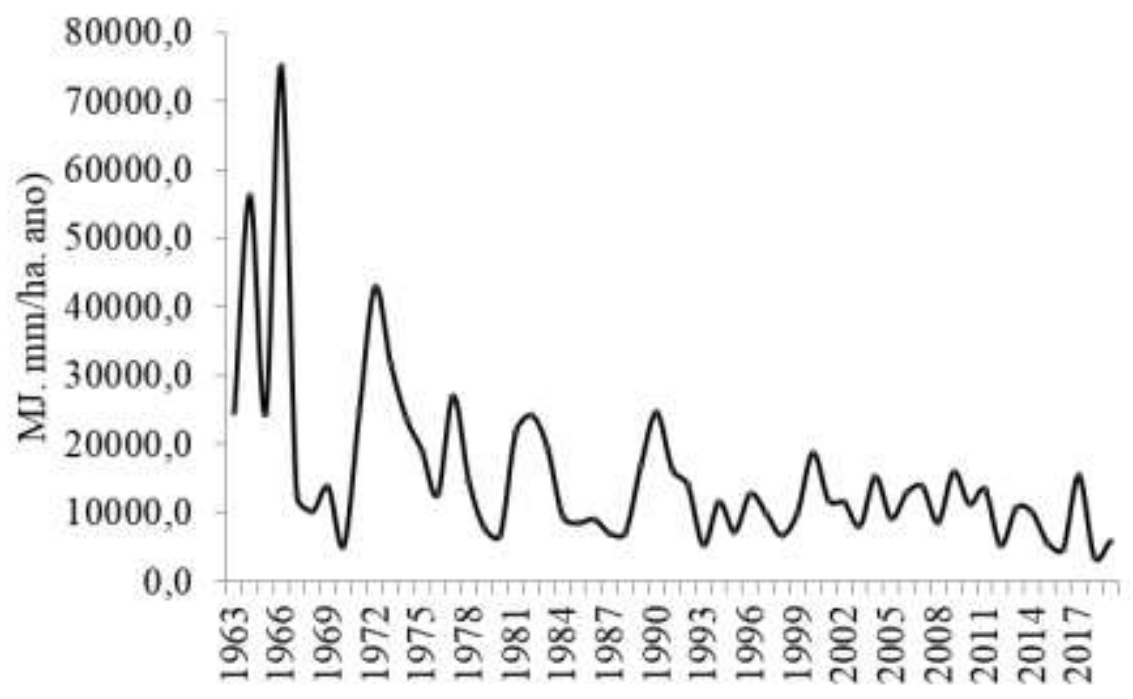

Fonte: Medeiros, (2020).

Tabela 1. Anos, total anual pluvial, total anual da evapotranspiração e evaporação e a relação entre evapotranspiração/precipitação e evaporação/precipitação. 
Research, Society and Development, v. 10, n. 17, e205101724621, 2021

(CC BY 4.0) | ISSN 2525-3409 | DOI: http://dx.doi.org/10.33448/rsd-v10i17.24621

\begin{tabular}{|c|c|c|c|c|c|}
\hline Anos & Chuva & etp & evr & (etp/prec)*100 & (evr/prec)*100 \\
\hline 1963 & 1574,3 & 156,1 & 98,4 & 9,9 & 6,2 \\
\hline 1964 & 2558,4 & 150,5 & 108,0 & 5,8 & 4,2 \\
\hline 1965 & 1565,3 & 168,5 & 116,4 & 10,7 & 7,4 \\
\hline 1966 & 3032,8 & 146,0 & 146,0 & 4,8 & 4,8 \\
\hline 1967 & 1050,7 & 117,9 & 117,9 & 11,2 & 11,2 \\
\hline 1968 & 934,3 & 93,9 & 93,9 & 10,0 & 10,0 \\
\hline 1969 & 1116,6 & 83,8 & 83,8 & 7,5 & 7,5 \\
\hline 1970 & 627,1 & 86,8 & 86,8 & 13,8 & 13,8 \\
\hline 1971 & 1578,8 & 96,8 & 77,6 & 6,1 & 4,9 \\
\hline 1972 & 2182,7 & 132,8 & 36,8 & 6,0 & 1,6 \\
\hline 1973 & 1828,3 & 151,9 & 49,01 & 8,3 & 2,6 \\
\hline 1974 & 1539,9 & 159,9 & 159,9 & 10,3 & 10,3 \\
\hline 1975 & 1352,3 & 164,2 & 43,1 & 12,1 & 3,1 \\
\hline 1976 & 1061,5 & 153,5 & 15,5 & 14,4 & 1,4 \\
\hline 1977 & 1663,5 & 167,3 & 167,3 & 10,03 & 10,0 \\
\hline 1978 & 1159,4 & 143,4 & 143,4 & 12,3 & 12,3 \\
\hline 1979 & 797,3 & 112,8 & 112,8 & 14,1 & 14,1 \\
\hline 1980 & 728,9 & 89,0 & 89,0 & 12,2 & 12,2 \\
\hline 1981 & 1464,0 & 78,1 & 78,1 & 5,3 & 5,3 \\
\hline 1982 & 1559,8 & 78,9 & 78,9 & 5,1 & 5,1 \\
\hline 1983 & 1377,8 & 88,1 & 88,1 & 6,4 & 6,4 \\
\hline 1984 & 895,6 & 121,2 & 105,0 & 13,5 & 11,7 \\
\hline 1985 & 840,4 & 135,1 & 67,9 & 16,1 & 8,1 \\
\hline 1986 & 874,0 & 141,8 & 141,8 & 16,2 & 16,2 \\
\hline 1987 & 751,5 & 148,8 & 143,5 & 19,8 & 19,1 \\
\hline 1988 & 752,5 & 146,4 & 47,3 & 19,5 & 6,3 \\
\hline 1989 & 1261,9 & 163,4 & 17,5 & 12,9 & 1,4 \\
\hline 1990 & 1338,1 & 142,6 & 142,6 & 10,7 & 10,7 \\
\hline 1991 & 1236,3 & $117-, 3$ & 117,3 & 9,5 & 9,5 \\
\hline 1992 & 918,9 & 92,8 & 92,8 & 10,1 & 10,1 \\
\hline 1993 & 635,4 & 80,6 & 80,6 & 12,7 & 12,7 \\
\hline 1994 & 1008,4 & 84,1 & 84,1 & 8,3 & 8,3 \\
\hline 1995 & 767,6 & 95,9 & 95,9 & 12,5 & 12,5 \\
\hline 1996 & 1069,0 & 131,6 & 131,6 & 12,3 & 12,3 \\
\hline 1997 & 923,6 & 149,9 & 149,9 & 16,2 & 16,2 \\
\hline 1998 & 731,8 & 159,6 & 154,8 & 21,8 & 21,2 \\
\hline 1999 & 921,5 & 164,0 & 121,3 & 17,8 & 13,2 \\
\hline 2000 & 1341,1 & 156,2 & 156,2 & 11,6 & 11,6 \\
\hline 2001 & 1020,2 & 172,5 & 172,5 & 16,9 & 16,9 \\
\hline 2002 & 1005,2 & 146,6 & 146,6 & 14,6 & 14,6 \\
\hline 2003 & 814,6 & 116,5 & 116,5 & 14,3 & 14,3 \\
\hline 2004 & 1187,4 & 93,3 & 93,3 & 7,9 & 7,9 \\
\hline 2005 & 881,2 & 80,9 & 80,9 & 9,2 & 9,2 \\
\hline 2006 & 1073,6 & 82,2 & 81,9 & 7,7 & 7,6 \\
\hline 2007 & 1120,2 & 93,3 & 93,3 & 8,3 & 8,3 \\
\hline 2008 & 847,4 & 126,7 & 77,3 & 15,0 & 9,1 \\
\hline 2009 & 1220,9 & 143,6 & 48,2 & 11,8 & 3,9 \\
\hline 2010 & $\begin{array}{l}991,9 \\
\end{array}$ & 152,1 & 53,8 & 15,3 & 5,4 \\
\hline 2011 & 1099,4 & 154,5 & 31,2 & 14,1 & 2,8 \\
\hline 2012 & 633,0 & 148,4 & 36,7 & 23,4 & 5,8 \\
\hline 2013 & 961,5 & 164,5 & 18,2 & 17,1 & 1,9 \\
\hline 2014 & 930,7 & 142,7 & 142,7 & 15,3 & 15,3 \\
\hline 2015 & 663,2 & 117,1 & 117,1 & 17,7 & 17,7 \\
\hline 2016 & 595,4 & 92,2 & 92,2 & 15,5 & 15,5 \\
\hline 2017 & 1192,8 & 77,9 & 77,9 & 6,5 & 6,5 \\
\hline 2018 & 498,8 & 80,4 & 80,4 & 16,1 & 16,1 \\
\hline
\end{tabular}


Research, Society and Development, v. 10, n. 17, e205101724621, 2021

(CC BY 4.0) | ISSN 2525-3409 | DOI: http://dx.doi.org/10.33448/rsd-v10i17.24621

\section{9}

675,2

90,5

85,2

13,4

12,6

Legenda: ETP = Evapotrnaspiração; EVR = evaporação. Fonte: Medeiros, (2020).

Na Tabela 1 têm-se as variabilidades dos índices evapotrnapiração/precipitação e evaporação/precipitação, estes valores significam que a ETP ou a EVR foram acima dos valores pluviométricos e seus números dizem dos seus percentuais em relação a chuva. As irregularidades de ambos os elementos são bastante distintas e explicativas.

\section{Conclusões}

Os resultados do balanço hídrico mostraram que as condições locais contidas pelo alto índice pluvial pode ocasionar elevada erosivibilidade e nos mostram que esta metodologia deve ser utilizada para estudos futuros envolvendo a mesma temática de iniciativa deste estudo em discussão.

As oscilações de redução e acréscimo na temperatura média verificadas neste estudo podem estar associadas ao crescimento urbano, desmatamento das áreas verdes, impermeabilização do solo, queimadas, focos de incêndios e o crescimento vertical da área urbana e rural. Estes elementos fazem com que uma maior parcela da sociedade viva nas cidades, fundindo aspectos de vida econômica, política, social e cultural, e como tal enfrentem um maior risco de danos climáticos.

A temperatura do ar apresenta aumento em todos os meses do ano, destacando-se a temperatura máxima, pelo aumento anômalo nos meses que compõem as estações de outono e primavera. Já para a temperatura mínima, o maior aumento é observado entre a primavera, verão e outono.

Os índices evapotranspirados mensais apresentam vinculação das coordenadas geográfica, principalmente, da orografia, além da compactação de solo (urbano e rural), o crescimento vertical e a falta de arborização próxima aos lençóis d'água que vêm acrescentando o poder evapotranspirastivo.

Os índices erosivos fluíram entre 7500 MJ. mm/ha.ano a 28000 MJ. mm/ha.ano, ressalta-se que este índice erosivo estão interligados as flutuações pluviais que registrou-se com grande magnitudes e em curto intervalo de tempo.

\section{Referências}

Alvares, C. A.; Stape, J. L., Sentelhas, P. C., Gonçalves, J. L. M. \& Sparovek, G. (2014). Köppen's climate classification map for Brazil. Meteorologische Zeitschrift v.22, 711-728.

Augusto, L. S. S., Gurgel, I. G. D., Neto, H. F. C., Melo, C. H. \& Costa, A. M. (2012). O contexto global e nacional frente aos desafios do acesso adequado à água para consumo humano. Revista Ciência \& Saúde Coletiva. 17(6), 1511-22. https://doi.org/10.1590/S1413-81232012000600015.

Borsato, V. A.; (2012). O balanço hídrico em Campo Mourão e os sistemas atmosféricos. Geografia, Rio Claro, SP, v. 37, n. 2, p. $255-270$.

Camargo, A. P. (1971). Balanço hídrico no Estado de São Paulo. Campinas: IAC, 28p. (Boletim Técnico, 116). Cavalcanti, EP, Silva, EDV. (1994). Estimativa da temperatura do ar em função das coordenadas locais. In: Congresso Brasileiro de Meteorologia, 8, Belo Horizonte, Anais...Belo Horizonte: SBMET, v.1, p.154-157.

Cavalcanti, E. P., Silva, V. P. R., Sousa, F. A. S. (2006). Programa computacional para a estimativa da temperatura do ar para a região Nordeste do Brasil. Revista Brasileira de Engenharia Agrícola e Ambiental. V.10, p.140-147.

França, M. V.; Medeiros, R. M.; Araújo, W. R.; Holanda, R. M. (2020). Balanço hídrico e suas variabilidades em período de El Niño e La Niña visando às oscilações erosivas em Amparo de São Francisco - Sergipe - Brasil. Research, Society and Development, v. 9, n. 9, e443996995, 2020 (CC BY 4.0), ISSN 2525-3409 | DOI: http://dx.doi.org/10.33448/rsd-v9i9.6995

França, M. V.; Medeiros, R. M.; Araújo, W. R.; Holanda, R. M. (2020). Balanço hídrico para diferentes capacidades de campo e a variabilidade erosiva pluvial no munícipio de Amparo de São Francisco - SE, Brasil. Research, Society and Development, v. 9, n. 9, eXX, (CC BY 4.0) ISSN 2525-3409.| DOI: http://dx.doi.org/10.33448/rsd-v9i9.XX

França, M. V.; Ferraz, J. X. V.; Medeiros, R. M.; Holanda, R. M \& Rolim Neto, F. C. (2019). Balanço hídrico entre $2000-2016$ e seu comparativo com o ano de 2016 e sua influência do armazenamento de água no solo no município de Serra Talhada - PE. Tecnologias no contexto das vulnerabilidades ambientais. 1 ed.: Editora Itacaiúnas, v.1, p. 357-365. 
Fu, G.; Charles, S. P.; Yu, J. (2009). A critical overview of pan evaporation trends over the last 50 years. Clim. Change, n.97, p.193-214.

Holanda, R. M.; Medeiros; R. M. (2019). Classificação climática pelo método de Köppen e Thornthwaite em Bom Jesus do Piauí, Brasil. Revista Pantaneira, $16,57-68$

Holanda, R. M.; Medeiros, R. M.; França, M. V.; Rolim Neto.; F. C. (2019). Índice de aridez na Zona da Mata no Estado de Pernambuco - BrasiL In: Tecnologias no contexto das vulnerabilidades ambientais [livro eletrônico.1 ed.: Editora Itacaiúnas, 2019, v.1, p. 461-473.

IPCC. Impacts, Adaptation, and Vulnerability. Part B: Regional Aspects. Working Group II Contribution to the Fifth Assessment Report of the Intergovernmental Panel on Climate Change. Intergovernmental Panel on Climate Change (IPCC). 2014.

Köppen, W. Grundriss der Klimakunde: Outline of climate science. Berlin: Walter de Gruyter. P.388. 1931.

Köppen, W.; Geiger, R. (1928). Klimate Der Erde. Gotha: Verlag Justus Perthes. Wallmap 150cmx200cm. 1928.

Marengo, J. A.; Schaeffer, R.; Zee, D.; Pinto, H. S. (2017). Mudanças climáticas e eventos extremos no Brasil. <http://www.fbds.org.br/cop15/ FBDS_MudancasClimaticas.pdf $>$.

Marengo, J.; Alves, L. M.; Beserra, E. A.; Lacerda, F. F. (2015). Variabilidade e mudanças climáticas no semiárido brasileiro. Recursos hídricos em regiões áridas e semiáridas. ISBN 978-85-64265-01-1. INSA. Pag. 303 - 422. Campina Grande-PB. 2015.

Matos, R. M.; Silva, P. F.; Medeiros, R. M.; Santos, B. D. B.; Barros, A. S.; Neto, J. D.; Saboya, 1. F (2020). Balanço hídrico climatológico normal e sequencial para o município de Barbalha - CE. Revista Brasileira de Geografia Física v.13, n.3 (2020) 973-982.

Matos, R. M.; Silva, P. F.; Barros, A. S.; Dantas Neto, J.; Medeiros, R. M.; Saboya, L. M. S.; Santos, B. D. B, (2019). Aptidão agroclimática para o cultivo da mandioca no município de Barbalha - CE. Revista Brasileira de Geografia Física [online] 12. https://doi.org/10.26848/rbgf.v12.5.p\%25p. Acesso: 26 jul. 2019.

Medeiros, R. M. (2020). Balanço hídrico sequencial em São Bento do Una - PE, Brasil, visando apoio a avicultura. Revista de Geografia (Recife) V. 37, No. 2,2020 .

Medeiros, R. M \& Holanda, R. M. (2020). Balanço hídrico sequencial para Lagoa Seca - Paraíba - Brasil. Research, Society and Development, 9(7):1-26. e643974691.

Medeiros, R. M.; Cavalcanti, E. P, (2020). Tendência climática das temperaturas do ar no município de Bom Jesus do Piauí, Brasil. Research, Society and Development, 9(7):1-23, e315973882.

Medeiros, R. M.; Holanda, R. M.; França, M. V.; Filho, M. C.; Piscoya, V. C.; Cunha, A. L. X.; Moreira, G. R.; Freitas, J. F.; Araújo Filho, R. N. (2020). Floating of the Average Temperature in the Area of Mata Pernambucana, Brazil. Ijsrm.Human, 2020; Vol. 15 (3), $63-83$.

Medeiros, R. M. (2019). Adaptação da planilha desenvolvida por ROLIM et al. no ambiente EXCEL para o cálculos de balanço hídricos sequencial.

Medeiros, R. M. (2019). Análise pluviométrica em Bom Jesus - PI, Brasil. Paisagens \& Geografias Volume 4, número 2, p. 22 - 35. jul.- dez. 2019. ISSN: 2525-5142.

Medeiros, R. M. (2018). Amplitudes térmicas e sua oscilação mensal na grande metrópole Recife-PE, Brasil. Paisagens \& Geografias, Revista da Unidade Acadêmica de Geografia Centro de Humanidades - UFCG. Volume 2, número 1, p.31-45. 2018.

Medeiros, R. M, (2016). Formulação do balanço hídrico em planilhas eletrônicas conforme base de Thornthwaite, CW.

Medeiros, R. M. (2016a). Estudo climatológico do município de Matinhas - PB. Editora da Universidade Federal de Campina Grande - EDUFCG. 1.a Edição. Campina Grande - PB.

Medeiros, R. M. (2016b) Estudo agroclimatológicos do Estado de Sergipe. p. 137.

Medeiros, R. M.; Matos, R. M.; Silva, P. F.; Silva, J. A. S. (2015). Caracterização climática e diagnóstico da aptidão agroclimática de culturas para Barbalha CE. Revista Enciclopédia Biosfera 11, 461-476.

Medeiros, R. M.; Gomes Filho, M. F. \& Costa Neto, F. A. (2014). Estudo da evapotraspirção de referencia mensal e anual sobre a bacia hidrografica do rio Uruçuí Preto - Piauí, Brasil In: $9^{\circ}$ Congresso de Educação Agrícola Superior Areia-PB -, 2014, Areia - PB. v.1. p.106 - 112

Passos, M. L. V.; Zambrzycki, G. C., Pereira, R. S. (2016). Balanço hídrico e classificação climática para uma determinada região de Chapadinha - MA. Revista Brasileira de Agricultura Irrigada [online] 10. Disponível: 10.7127/rbai.v10n400402. Acesso: 04 jul. 2019.

Rocha, G. S.; Pinheiro, A. V. R. \& Costa, C. E. A. S. (2020). Gestão dos Recursos Hídricos no Município de Parauapebas (PA): Avaliação dos Usos, Alteração dos Cenários e Possíveis Impactos. Research, Society and Development, 9. https://doi.org/http://dx.doi.org/10.33448/rsd-v9i4.3042 Gestão.

Roderick, M. L.; Hobbins, M. T.; Farquhar, G. D. (2009). Pan evaporation trends and the terrestrial water balance. I. Principles and observations. Geogr. Compass, n.3, v.2, p.746-760.

Rolim, G. S, Sentelhas, P. C, \& Barbieri, V. (1998). Planilhas no ambiente EXCEL para os cálculos de balanços hídricos: normal, sequencial de cultura e de produtividade real e potencial. Revista Brasileira de Agrometeorologia, Santa Maria, v. 6,n.1,p133-137. 
Research, Society and Development, v. 10, n. 17, e205101724621, 2021

(CC BY 4.0) | ISSN 2525-3409 | DOI: http://dx.doi.org/10.33448/rsd-v10i17.24621

Silva, C. J; Franca, M. V; Medeiros, R. M; Holanda, R. M. (2019). O índice de aridez e sua tendência à desertificação na bacia do Rio Ipojuca-PE. Journal of Environmental Analysis and Progress. , v.4, p.21 - 30, 2019.

SUDENE. (1990). Normais Climatológicas da Área da SUDENE. Superintendência do Desenvolvimento do Nordeste. Convênio com o Serviço de Meteorologia, Recife.

Thornthwaite, C. W. (1948). An approach toward a rational classification of climate. Geogr. Rev, v.38, p.55-94.

Thornthwaite, CW.; Mather, J. R. (1955). The water balance. Publications in Climatology.New Jersey: Drexel Institute of Technology, 104p.

Vilar, H. N; Medeiros, R. M. (2019). Índice de aridez na Zona da Mata no Estado de Pernambuco - Brasil. Journal of Environmental Analysis and Progress., v.04, p.14 - 20, 2019.

Xavier, R. A.; Dornellas, P. C. (2005). Análise do comportamento das chuvas no município de Arapiraca, Região Agreste de Alagoas. Revista de Geografia, v.14, n.2. 